\title{
Reaproveitamento de sabugo de milho para potencial remoção de formulação comercial de glifosato em fase aquosa pela técnica de adsorção
} Corn cob reuse in the adsorption of a commercial formulation of glyphosate Nayara Valéria Assis Marcelino* $\odot$, Renata Medici Frayne Cuba' $\odot$, Francisco Javier Cuba Teran' ${ }^{\circledR}$

口-

\begin{abstract}
RESUMO
Neste estudo, foi produzido biocarvão de sabugo de milho ativado com ácido fosfórico (BCA) para potencial remoção do herbicida glifosato - GLF (formulação comercial) em meio aquoso. O BCA foi caracterizado por análises de difração de raios $X$, espectroscopia de infravermelho, adsorção e dessorção de $N_{2}$, microscopia eletrônica de varredura e determinação do potencial de carga zero. $\mathrm{O}$ efeito do $\mathrm{pH}$ inicial e da massa de adsorvente também foi avaliado. Os resultados cinéticos de adsorção foram ajustados aos modelos de pseudoprimeira e pseudossegunda ordem. A natureza do processo foi estudada por meio dos modelos de isoterma de Langmuir e Freundlich, e os parâmetros termodinâmicos calculados para as temperaturas de 23, 43 e $63^{\circ} \mathrm{C}$. Os resultados obtidos demonstraram que a adsorção de GLF no BCA foi dependente da temperatura, da massa de adsorvente e do $\mathrm{pH}$ do meio, com a melhor condição de ensaio caracterizada por $63^{\circ} \mathrm{C}, 0,25 \mathrm{~g}$ de $\mathrm{BCA}$ e $\mathrm{pH}=7$, resultando em boa eficiência de remoção (62,67\%), porém com baixa capacidade de adsorção (2,67 mg.g'). A cinética de adsorção foi representada pelo modelo de pseudossegunda ordem e considerada rápida, sendo necessários 15 min para atingir 98\% da capacidade máxima de adsorção. Os dados da isoterma foram bem descritos pelo modelo de Freundlich. Por fim, o estudo termodinâmico revela que a adsorção de GLF é de natureza endotérmica $\left(\Delta \mathrm{H}^{\circ}>0\right)$ e endergônica $\left(\Delta \mathrm{G}^{\circ}>0\right)$ ). Os resultados apresentados confirmam que o BCA de sabugo de milho é um adsorvente capaz de remover GLF (formulação comercial) do meio aquoso.
\end{abstract}

Palavras-chave: sabugo de milho; herbicida; carvão ativado; tratamento de água.

\begin{abstract}
In this study a biochar was produced from corn cob (BCA), which was activated with phosphoric acid to verify its potential for removal of herbicide glyphosate (GLF) (commercial formula) in aqueous media. BCA was characterized by X-ray diffraction spectroscopy, infrared spectroscopy, sorption and desorption of N2. scanning electron microscope, and zero charge potential. Kinetic results of adsorption were adjusted to pseudo-first and pseudo-second order reactions. The adsorption process was studied to verify if it followed Freundlich and Langmuir isotherms, and the thermodynamic parameter was calculated for $23^{\circ} \mathrm{C}, 43{ }^{\circ} \mathrm{C}$ and $63{ }^{\circ} \mathrm{C}$. The results showed that adsorption of GLF on BCA depended on temperature, adsorbent mass, and $\mathrm{pH}$. The best results were obtained for the temperature of $63{ }^{\circ} \mathrm{C}$ with $0.25 \mathrm{~g}$ de $\mathrm{GLF}$ and $\mathrm{pH}=7.0$ conditions that presented $62.3 \%$ of GLF removal and low adsorption capacity (2.67 mg. $\mathrm{g}^{1}$ ). That was probably due to the porous nature of BCA and Coadsorption of other constituents that were present in the commercial formula of GLF. The adsorption kinetics was represented by the model of pseudosecond order and considered fast, taking 15 min to reach 98\% of the maximum adsorption capacity. The isotherm data were well represented by the Freundlich model. Finally, the thermodynamic study demonstrated that the adsorption of $\mathrm{GLF}$ is of endothermic nature $\left(\Delta \mathrm{H}^{\circ}>0\right)$ and endergonic $\left(\Delta \mathrm{GO}^{\circ}>0\right)$. The results confirmed that BCA from corn cob is an adsorbent capable of removing GLF (commercial formula) from aqueous media. However, the endothermic nature of the process can compromise its performance in water treatment processes.
\end{abstract} Keywords: corn cob; herbicide; activated carbon; water treatment.

\section{INTRODUÇÃO}

O desenvolvimento tecnológico da sociedade moderna ocasionou diversos problemas ambientais alterando a qualidade do ar, do solo e, principalmente, da água. As indústrias são as principais fontes poluidoras dos recursos hídricos, uma vez que seus processos podem gerar elevada quantidade de resíduos, tais como: água de lavagem, subprodutos de reações químicas e efluentes contendo corantes, alimentos, agrotóxicos, fármacos, entre outros (MARQUES; AMÉRICO-PINHEIRO, 2018).

Atualmente, há uma crescente preocupação com relação aos micropoluentes químicos, que estão presentes no meio ambiente em concentrações na ordem de $\mu$ g. $L^{-1}$ e ng. $L^{-1}$ (COOK et al., 2016). Grande parte desses micropoluentes, dos

$\square$

'Escola de Engenharia Civil e Ambiental, Universidade Federal de Goiás - Goiânia (GO), Brasil.

*Autora correspondente: nayaravaleria@hotmail.com

Conflitos de interesse: os autores declaram não haver conflito de interesses.

Financiamento: nenhum.

Recebido: 16/03/202O - Aceito: 15/07/2O2O - Reg. ABES: 20200088 
quais se destacam os interferentes ou desreguladores endócrinos (DE), pode interagir negativamente com os seres vivos causando danos ou alterações nas funções do sistema endócrino, como a endometriose, e aumento na ocorrência de câncer de mama, testículo e próstata (JARDIM, 2017).

Existem diversas classes de substâncias que são classificadas como DE, entre elas, as substâncias sintéticas (ftalatos, alquilfenóis, organoclorados, bisfenóis, parabenos, policlorados de bifeninas), os pesticidas (inseticidas, herbicidas, fungicidas), as substâncias de uso farmacêutico e as substâncias naturais (estrogênios naturais e fitoestrogênios) (WESTERHOFF et al., 2005; BILA; DEZOTTI, 2007).

Entre essas substâncias de potencial interferência no sistema endócrino, destaca-se o herbicida glifosato (GLF), cujo ingrediente ativo ocupa o primeiro lugar entre os quatro agroquímicos mais utilizados no Brasil, com 173.150,75 toneladas comercializadas em 2017, sendo empregado, principalmente, na cultura de soja e cana-de-açúcar (BOMBARDI, 2017).

$\mathrm{O}$ GLF ( $\mathrm{N}$-fosfonometilglicina/ $\mathrm{C}_{3} \mathrm{H}_{8} \mathrm{NO}_{5} \mathrm{P}$ ) é um herbicida não seletivo, sistêmico, pós-emergente e apresenta elevada eficiência na eliminação de ervas daninhas monocotiledôneas e dicotiledôneas. Além dos agroquímicos, o GLF também compõe a fórmula de produtos domissanitários utilizados em jardinagem amadora e áreas não agricultáveis, como ao lado de rodovias para regular o crescimento de plantas, o que torna a exposição ao ingrediente ativo altamente prevalente na população em geral (KHOURY et al., 2010).

Embora o uso do composto seja em solo, em razão da utilização extensiva do herbicida, seu alcance pode atingir os mananciais subterrâneos e superficiais por meio da lixiviação e do carreamento superficial.

A principal fonte de exposição do GLF para os organismos vivos é a ingestão de água, visto que os sistemas convencionais de tratamento de água e efluentes não são capazes de remover ou degradar por completo uma série de compostos orgânicos sintéticos, como o GLF (HU; ZHAO; SOROHAN, 2011; GWENZI et al., 2017).

O Anexo VII da Portaria no 5/2017 do Ministério da Saúde (BRASIL, 2017) estabelece, para o GLF e seu metabólito, o ácido aminometilfosfônico (AMPA), concentração máxima de $500 \mu \mathrm{g} . \mathrm{L}^{-1}$. Já a Resolução do Conselho Nacional do Meio Ambiente (CONAMA) nº 357, de 17 de março de 2005, que classifica os corpos d'água, estabelece para as águas doces de Classes 1 e 2 concentrações máximas de GLF de $65 \mu \mathrm{g} . \mathrm{L}^{-1}$ e para a Classe 3, um máximo de 280 $\mu \mathrm{g} . \mathrm{L}^{-1}$ (BRASIL, 2005).

Diferentes são os métodos apresentados na literatura para a remoção de GLF em meio aquoso, que incluem osmose reversa, precipitação, coagulação, degradação química, oxidação química, nanofiltração, oxidação avançada, degradação eletroquímica, degradação fotocatalítica, degradação microbiana e adsorção (CUI et al., 2012).

Frequentemente, a adsorção em carvão ativado é considerada em relação a outras tecnologias de tratamento, em vista de o fenômeno ser adaptável a diferentes aplicações e os adsorventes não serem considerados potencialmente tóxicos ao manusear e apresentarem possibilidade de regeneração (HERATH; POH; NG, 2019). No entanto, em alguns casos, os carvões ativados utilizados como adsorventes, embora sejam eficientes, apresentam altos custos de preparação e regenaração (STREIT et al., 2019), de forma que pesquisadores têm estudado sua substituição pelo biocarvão, cujas características físico-químicas, como elevadas área superficial e densidade de cargas, bem como estrutura altamente aromática e porosa, contribuem para a alta capacidade de adsorção $-\mathrm{q}_{\mathrm{eq}}$ (MAYAKADUWA et al., 2016).
Comparada com os métodos convencionais para o preparo de outros materiais carbonáceos, a pirólise empregada para a produção de biocarvão é considerada de baixo custo (WANG; WANG, 2019), em razão do menor gasto energético decorrente das menores temperaturas empregadas $\left(300\right.$ a $\left.900^{\circ} \mathrm{C}\right)$ e da baixa produção de poluentes secundários (LU et al., 2012; RAJASULOCHANA; PREETHY, 2016).

Ainda, como o biocarvão pode ser produzido a partir da pirólise de vários tipos de subprodutos originados em atividades antrópicas, como os resíduos agroindustriais, sua aplicação como adsorvente pode tornar o método de tratamento mais econômico e ambientalmente sustentável.

Estudos anteriores investigaram a adsorção de GLF em biocarvão produzido a partir de diferentes matérias-primas, incluindo madeira (HERATH; POH; NG, 2019; MAYAKADUWA et al., 2016), palma (modificado com nanopartículas de ferro) (JIANG et al., 2018), casca de arroz (HERATH et al., 2016) e casca de eucalipto (SEN; DATTA; MONDAL, 2019). No entanto, não foi possível identificar estudos que investigaram biocarvão produzido a partir do sabugo de milho para a remoção de GLF (formulação comercial).

O sabugo de milho como material precurssor do biocarvão é interessante em razao do elevado teor de carbono (42\%) (LOPES et al., 2013) e da alta disponibilidade, já que representa $13 \%$ do quantitativo da produção de milho (SALES et al., 2015), cuja projeção nacional, considerando a primeira, a segunda e a terceira safras na temporada 2019/2020, deverá alcançar uma produção recorde de 101 milhões de toneladas (CONAB, 2020).

Nesse sentido, o presente estudo teve como objetivo analisar o reaproveitamento de sabugo de milho para a produção de biocarvão ativado (BCA) visando ao seu uso como adsorvente para a remoção do GLF (formulação comercial) em meio aquoso.

\section{METODOLOGIA}

\section{Materiais e reagentes}

Os reagentes utilizados foram de grau analítico, com exceção da solução de GLF preparada a partir do produto comercial Roundup ${ }^{\circledast}$ Original DI da indústria Monsanto, à base de sal de Di-amônio de N-(fosfonometil) glicina (445 g.L $\mathrm{L}^{-1}$ ), equivalente a 370 g.L $\mathrm{L}^{-1}$ do ácido $\mathrm{N}$-(fosfonometil) glicina.

\section{Produção de biocarvão ativado}

O sabugo de milho foi cedido por comerciantes de feira livre localizada na região central de Goiânia. O material foi cortado em cubos com dimensões aproximadas de $1 \mathrm{~cm} \times 1 \mathrm{~cm} \times 1 \mathrm{~cm}$ e secos em estufa (Nova Ética) à temperatura de $105^{\circ} \mathrm{C}$ por $24 \mathrm{~h}$. Em seguida, o sabugo seco foi acondicionado em cadinho, pesado e o conjunto embalado em papel alumínio, de acordo com o método proposto por Nourouzi, Chuah e Choong (2010), para garantir uma atmosfera pobre em oxigênio. O material foi carbonizado em forno mufla (Quimis) durante $3 \mathrm{~h}$ a $500^{\circ} \mathrm{C}$, como proposto por Sales et al. (2015).

A ativação do biocarvão obtido foi realizada de acordo com o procedimento proposto por Sen, Datta e Mondal (2019). Primeiramente, o biocarvão foi impregnado com solução de ácido fosfórico $\left(\mathrm{H}_{3} \mathrm{PO}_{4}\right) 6 \mathrm{~N}$ em uma proporção de 1:3 (massa de biocarvão/volume de ácido) e a mistura foi mantida em estufa (Quimis) a $60 \pm 2^{\circ} \mathrm{C}$ por $24 \mathrm{~h}$. Após o período de ativação, foi realizada a neutralização do $\mathrm{H}_{3} \mathrm{PO}_{4}$ residual com solução de hidróxido de sódio $(\mathrm{NaOH})$ 
$0,1 \mathrm{~N}$ e, em seguida, o material obtido foi lavado com metanol $20 \%$, água deionizada, seco em estufa a $105 \pm 2^{\circ} \mathrm{C}$ e então armazenado em recipiente hermético à temperatura ambiente.

\section{Caracterização das propriedades químicas e físicas do biocarvão de sabugo de milho ativado com ácido fosfórico}

A granulometria do material foi determinada por meio de ensaio granulométrico utilizando o conjunto de peneiras graduadas pentencentes à série de Tyler (Bertel). O ponto de carga zero $\left(\mathrm{pH}_{\mathrm{PCZ}}\right)$ foi avaliado por meio do "experimento dos 11 pontos" (PARK; REGALBUTO, 1995).

A morfologia da superfície do biocarvão foi observada em Microscópio Eletrônico de Varredura (MEV) da marca JEOL JSM - 6610, e a composição elementar foi obtida por espectroscopia de raios X por dispersão em energia (EDX) em equipamento Energy Dispersive Spectroscopy (EDS) Thermo scientific NSS Spectral Imaging

As propriedades texturais e de superfície do biocarvão foram determinadas a partir das isotermas de adsorção-dessorção de $\mathrm{N}_{2}\left(-196^{\circ} \mathrm{C}\right)$ utilizando equipamento ASAP (Acelerated surface área and porosimetry). Para a determinação da área superficial, o método empregado foi o método BET ou Teoria de Adsorção Multimolecular (BRUNAUER; EMMETT; TELLER; 1938). O volume total de poros foi obtido da isoterma de dessorção a partir do volume de $\mathrm{N}_{2}$ dessorvido na pressão relativa $\left(\mathrm{P} / \mathrm{P}_{0}\right)$ de 0,95 , enquanto o diâmetro médio e a distribuição dos poros foram determinados pelo método BJH (BARRETT; JOYNER; HALENDA, 1951).

A estrutura cristalina foi determinada por difração de raio X (DRX) em difratômetro Bruker D8 Discover. Por fim, os grupos funcionais da superfície do biocarvão, antes e após o carregamento do GLF, foram analisados por espectroscopia no infravermelho por transformada de Fourier (FTIR) (Bruker Vertex 70), na faixa de $400 \mathrm{a} 4.000 \mathrm{~cm}^{-1}$.

\section{Análises físico-químicas}

As análises de GLF foram realizadas de acordo com o método proposto por Tzaskos et al. (2012), que consistiu em misturar $5 \mathrm{~mL}$ da amostra em $0,5 \mathrm{~mL}$ de ninidrina (5\%) e 0,5 $\mathrm{mL}$ de molibidato de sódio (5\%). A mistura foi aquecida em banho-maria (Tecnal - TE057) por $12 \mathrm{~min}$ a $92 \pm 1^{\circ} \mathrm{C}$ para a formação do produto púrpura de Ruhemann, com máxima absorção em $570 \mathrm{~nm}$.

Previamente à análise de GLF, as amostras foram filtradas em sistema de bomba a vácuo com membranas de fibra de vidro e porosidade de $0,47 \mu \mathrm{m}$. As leituras da concentração de GLF foram realizadas em espectrofotômetro Hach Dr 5000.

A curva de calibração (coeficiente de determinação $-\mathrm{R}^{2}=0,9909$ ) foi construída usando soluções preparadas a partir da solução comercial empregada nos ensaios para evitar possível interferência de outros constituintes presentes na formulação comercial quando comparado com o produto puro (PEREIRA, 2010).

A determinação dos valores de $\mathrm{pH}$ foi realizada por método potenciométrico utilizando pHmetro digital (Tecnal).

\section{Testes preliminares de adsorção de glifosato}

Inicialmente, foram realizados ensaios para determinar a influência do $\mathrm{pH}$ e da massa inicial de BCA na adsorção do GLF. Em ambos os ensaios, foi utilizada solução de GLF com concentração de $12 \mathrm{mg} \cdot \mathrm{L}^{-1}$ preparada a partir de solução estoque com $500 \mathrm{mg} \cdot \mathrm{L}^{-1}$. A concentração da solução de GLF adotada nos ensaios foi em função de trabalhos prévios apresentados na literatura por Hu, Zhao e Sorohan (2011), Herath et al. (2016), Mayakaduwa et al. (2016) e Herath, Poh e Ng (2019).

Para avaliar o efeito do $\mathrm{pH}$ inicial no processo de adsorção, 0,5 g de BCA foi adicionado a $50 \mathrm{~mL}$ de solução de GLF com o $\mathrm{pH}$ previamente ajustado para os valores 1,$5 ; 2,5 ; 4 ; 7$; e 11, com soluções de ácido clorídrico $(\mathrm{HCl})$ ou $\mathrm{NaOH}$, ambas $0,1 \mathrm{M}$. Os valores de $\mathrm{pH}$ foram adotados levando em consideração a prevalência das diferentes espécies dissociadas da molécula de GLF em função dos intervalos de pHs, sendo eles: $\mathrm{pH}<2 ; 2<\mathrm{pH}<2,6 ; 2,6<\mathrm{pH}<5,6$; $5,6<\mathrm{pH}<10,6$ e pH $>10,6$. O valor de $\mathrm{pH}$ que propiciou a maior remoção de GLF (mg. $\left.\mathrm{g}^{-1}\right)$ foi adotado nos demais ensaios de adsorção.

Já o efeito da massa inicial de BCA no processo de adsorção foi avaliado adicionando distintas massas de BCA $(0,25 ; 0,5 ; 0,75 ; 1 ;$ e $1,5 \mathrm{~g})$ a $50 \mathrm{~mL}$ de solução de GLF com pH previamente ajustado para melhor condição de adsorção.

Em ambos os ensaios, as soluções foram mantidas sob agitação constante de $120 \mathrm{rpm}$ e temperatura de $23 \pm 2^{\circ} \mathrm{C}$ por $24 \mathrm{~h}$ em mesa agitadora orbital (Solab SL-180/A). Após esse período, a concentração remanescente de GLF foi determinada. Essas análises foram realizadas em triplicata com um branco para cada $\mathrm{pH}$ e massa de BCA.

A porcentagem de remoção (\%R) e a $\mathrm{q}_{\mathrm{eq}}$ de GLF foram calculadas usando as Equações 1 e 2, respectivamente (TAN; AHMAD; HAMEED, 2008; MONDAL et al., 2019):

$\% R=\frac{\left(C_{0}-C_{e q}\right) * 100}{C_{0}}$

$q_{e q}=\frac{\left(C_{0}-C_{e q}\right) v}{m}$

Em que:

$\mathrm{C}_{0}=$ concentração inicial de GLF (mg.L-1 $)$;

$\mathrm{C}_{\mathrm{eq}}=$ concentração de GLF no equilíbrio $\left(\mathrm{mg} \cdot \mathrm{L}^{-1}\right)$;

$\mathrm{V}=$ volume da solução $(\mathrm{L})$;

$\mathrm{m}=$ massa de BCA $(\mathrm{g})$.

\section{Cinética e capacidade de adsorção do glifosato}

Os dados cinéticos de adsorção e o tempo de equilíbrio foram obtidos em ensaio de batelada, em que se misturou, em diferentes frascos, $50 \mathrm{~mL}$ de solução de GLF (12 mg.L $\left.\mathrm{L}^{-1}\right)$ com 0,25 g de BCA. Os frascos foram mantidos sob agitação constante de $120 \mathrm{rpm}$ em mesa agitadora orbital (Solab SL-180/A) e temperatura ambiente de $23 \pm 2^{\circ} \mathrm{C}$. Em intervalos de tempo predeterminados, um frasco era retirado e a concentração remascente de GLF estabelecida. Esse procedimento foi realizado até o equilíbrio do sistema, verificado por meio da estabilização da concentração remanescente de GLF em solução.

Os dados do ensaio cinético de adsorção de GLF foram ajustados aos modelos de pseudoprimeira ordem (LAGERGREN, 1898) e de pseudossegunda ordem (HO; McKAY; 1998), conforme as Equações 3 e 4, respectivamente. O ajuste aos modelos foi avaliado por meio do $\mathrm{R}^{2} \mathrm{e}$ da comparação entre a $\mathrm{q}_{\mathrm{eq}}$ teórica (do modelo) e a obtida experimentalmente.

$$
\begin{aligned}
& \ln \left(q_{e q}-q_{\mathrm{t}}\right)=\ln q_{e q}-k_{1} t \\
& \frac{\mathrm{t}}{\mathrm{q}_{\mathrm{t}}}=\frac{1}{\mathrm{k}_{2} \mathrm{q}_{\mathrm{eq}}^{2}}+\frac{1}{\mathrm{q}_{\mathrm{eq}}}
\end{aligned}
$$


Em que:

$\ln =$ logaritmo natural;

$\mathrm{q}_{\mathrm{eq}}$ e $\mathrm{q}_{\mathrm{t}}=$ quantidades adsorvidas por grama de adsorvente no equilíbrio e no tempo t, respectivamente $\left(\mathrm{mg} \cdot \mathrm{g}^{-1}\right)$;

$\mathrm{k}_{1}=$ constante da taxa de adsorção de pseudoprimeira ordem $\left(\mathrm{min}^{-1}\right)$;

$\mathrm{k}_{2}=$ constante da taxa de adsorção de pseudossegunda ordem $\left(\mathrm{g} \cdot \mathrm{mg}^{-1} \cdot \mathrm{min}^{-1}\right)$; $\mathrm{t}=$ tempo $(\mathrm{min})$.

A capacidade e a natureza da adsorção do GLF foram determinadas usando os modelos isotérmicos de Langmuir e Freundlich (Equações 5 e 6). Para a obtenção dos dados experimentais, foram adicionados $0,25 \mathrm{~g}$ de BCA em $50 \mathrm{~mL}$ de solução de GLF com concentrações de 2,5; 5; 10; 15; 20; e 25 mg.L $\mathrm{L}^{-1}$. As misturas foram submetidas à agitação constante de $120 \mathrm{rpm}$ em mesa agitadora orbital (Solab SL-180/A) e a três temperaturas $\left(23 \pm 2^{\circ} \mathrm{C}, 43 \pm 2^{\circ} \mathrm{C}\right.$ e $63 \pm 2^{\circ} \mathrm{C}$ ). O tempo de ensaio adotado foi o tempo de equilíbrio obtido no ensaio cinético.

$\frac{C_{e q}}{q_{e q}}=\frac{1}{q_{\text {máx }}} C_{e q}+\frac{1}{K_{L} q_{\text {máx }}}$

$\ln q_{e q}=\ln K_{F}+\frac{1}{n} \ln C_{e q}$

Em que:

$\mathrm{K}_{\mathrm{L}}$ = constante de interação entre $\mathrm{o}$ adsorvido e $\mathrm{o}$ adsorvente $\left(\mathrm{mg} \cdot \mathrm{L}^{-1}\right)$. Elevados valores de $\mathrm{K}_{\mathrm{L}}$ indicam forte afinidade do adsorvato pelos sítios do adsorvente; $\mathrm{q}_{\text {máx }}=$ número total de sítios disponíveis no material adsorvente, ou seja, a capacidade de adsorção máxima (mg. $\mathrm{g}^{-1}$ );

$\mathrm{K}_{\mathrm{F}}=$ constante de Freundlich relacionada à capacidade de adsorção $\left[\left(\mathrm{mg} \mathrm{g}^{-1}\right)\right.$ $\left.\left(\mathrm{mg} . \mathrm{L}^{-1}\right) 1 / \mathrm{n}\right]$

$\mathrm{n}=$ constante de Freundlich relacionada à intensidade de adsorção. Indica se a isotérmica é favorável ou desfavorável, sendo favorável quando possui valores na faixa de 1 a 10 . Quanto maior o valor de $n$, maior a interação entre adsorbato e adsorvente.

Ainda, é possível expressar as características essenciais da isoterma de Langmuir por meio do fator de separação $\mathrm{R}_{\mathrm{L}}$, calculado por meio da Equação 7 .

$R_{L}=\frac{1}{1+R_{L} C_{i}}$

Em que:

$\mathrm{C}_{\mathrm{i}}=$ maior concentração inicial de adsorbato $\left(\mathrm{mg} \cdot \mathrm{L}^{-1}\right)$;

$\mathrm{R}_{\mathrm{L}}=$ usado para a interpretação do processo de adsorção, sendo: processo irreversível $\left(\mathrm{R}_{\mathrm{L}}=0\right)$, favorável $\left(0<\mathrm{R}_{\mathrm{L}}<1\right)$, linear $\left(\mathrm{R}_{\mathrm{L}}=1\right)$ ou desfavorável $\left(\mathrm{R}_{\mathrm{L}}>1\right)$ (CASTRO et al., 2017).

A qualidade dos ajustes foi avaliada por meio do $\mathrm{R}^{2} \mathrm{e}$ da comparação entre a $\mathrm{q}_{\mathrm{eq}}$ teórica (do modelo) e a $\mathrm{q}_{\mathrm{eq}}$ obtida experimentalmente.

\section{Termodinâmica de adsorção}

O estudo termodinâmico de adsorção foi desenvolvido para as temperaturas de $23 \pm 2^{\circ} \mathrm{C}(296 \mathrm{~K}), 43 \pm 2^{\circ} \mathrm{C}(316 \mathrm{~K})$ e $63 \pm 2^{\circ} \mathrm{C}(336 \mathrm{~K})$. Os valores das propriedades termodinâmicas energia livre de Gibs $\left(\Delta \mathrm{G}^{\circ}\right)$, variação da entropia $\left(\Delta \mathrm{S}^{\circ}\right)$ e variação da entalpia $\left(\Delta \mathrm{H}^{\circ}\right)$ foram calculados a partir das isotermas de adsorção do GLF $\left(\mathrm{q}_{\mathrm{eq}}\right.$ versus $\mathrm{C}_{\mathrm{eq}}$ ), em que se é possível calcular a constante de equilíbrio termodinâmico $\mathrm{K}_{\mathrm{D}}$ por meio da construção de um gráfico de $\ln \left(\mathrm{q}_{\mathrm{eq}} / \mathrm{C}_{\mathrm{eq}}\right)$ versus $\mathrm{q}_{\mathrm{eq}}$, extrapolando-se para $\mathrm{q}_{\mathrm{eq}}=0$. Com os valores de $\mathrm{K}_{\mathrm{D}}$ para cada temperatura, foi construído um gráfico de $\ln \mathrm{K}_{\mathrm{D}}$ versus $1 / \mathrm{T}$ para o cálculo da entropia e da entalpia pela Equação 8. A $\Delta \mathrm{G}^{\circ}$ foi calculada pela Equação 9.

$\ln K_{D}=\Delta S^{\circ} / R-\Delta H^{\circ} / R T$

$\Delta G_{a d s}^{\circ}=-R T \ln \left(K_{D}\right)$

Em que:

$\mathrm{R}=$ constante dos gases $\left(8,314 \mathrm{~J} \mathrm{mols}^{-1} \cdot \mathrm{K}^{-1}\right)$;

$\mathrm{T}=$ temperatura $(\mathrm{K})$.

\section{RESULTADOS E DISCUSSÃO}

\section{Caracterização do adsorvente}

Os parâmetros obtidos para a caracterização do BCA a partir dos ensaios granulométricos (BET, BJH, MEV, EDS, DRX e $\mathrm{pH}_{\mathrm{PCZ}}$ ) estão na Tabela 1.

A isoterma de adsorção e dessorção de $\mathrm{N}_{2}$ a $-196^{\circ} \mathrm{C}$ do BCA, bem como a distribuição de tamanho de poros, são apresentadas nas Figuras $1 \mathrm{~A}$ e 1B, respectivamente.

Observa-se, na Figura 1A, que o adsorvente apresenta isoterma tipo III, que, segundo Thommes et al. (2015), é típica de adsorventes que possuem grande variação no tamanho dos poros. Quanto à distribuição de tamanho de poros do BCA, o maior volume médio de poros apresentou diâmetro de, aproximadamente, $35 \AA ̊$ (Figura 1B), equivalente a mesoporos, de acordo com Ruthven (1984).

Sen, Datta e Mondal (2019) produziram carvão ativado da casca de eucalipto com área superficial igual a $0,54 \mathrm{~m}^{2} \cdot \mathrm{g}^{-1}$; o método de ativação química empregado por eles $\left(\mathrm{H}_{3} \mathrm{PO}_{4} 6 \mathrm{~N}\right)$ foi replicado no presente estudo e conduziu a resultado significativamente maior em se tratando de área superficial (Tabela 1), provavelmente em razão de o material precursor dos autores (casca de eucalipto) ser diferente do utilizado no presente estudo. Wang et al. (2018) explicam que as propriedades físico-químicas características de um biocarvão também são função do material precursor, além das condições de pirólise e ativação.

Com relação à maior presença de mesoporos que conformam a superfície do BCA, essa característica pode estar relacionada com o agente ativante utilizado, no caso o $\mathrm{H}_{3} \mathrm{PO}_{4}$. Heidari et al. (2014), ao compararem as características

Tabela 1 - Caracterização geral do biocarvão de sabugo de milho ativado com ácido fosfórico.

\begin{tabular}{l|c}
\hline Diâmetro médio dos grãos & $0,07 \mathrm{~mm}$ \\
\hline Área superficial & $34,126 \mathrm{~m}^{2} \cdot \mathrm{g}^{-1}$ \\
\hline Volume total de poros & $0,0498 \mathrm{~cm}^{3} \cdot \mathrm{g}^{-1}$ \\
\hline Tipologia & Mesoporosa \\
\hline Morfologia & Superfície irregular \\
\hline Composição elementar & C, $\mathrm{Na}$ e P \\
\hline Estrutura cristalina & Sólido amorfo \\
\hline $\mathrm{pH}$ & 8,0 \\
\hline PCZ &
\end{tabular}

Fonte: elaborada pelos autores. 
A

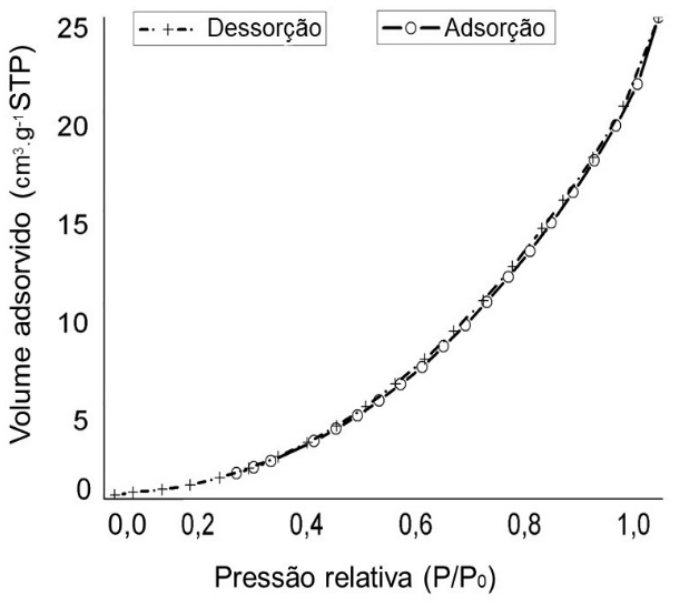

B

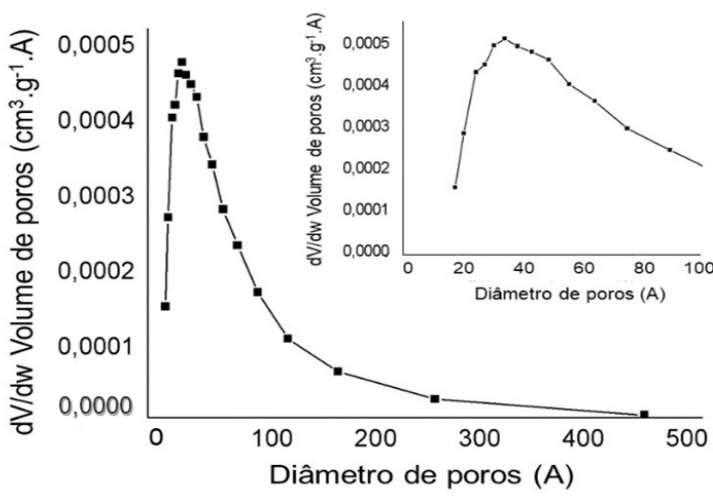

Fonte: os autores

Figura 1 - Isotermas de (A) adsorção/dessorção de $\mathrm{N}_{2}\left(-196^{\circ} \mathrm{C}\right)$ e (B) distribuição de tamanho de poros.

físico-químicas de biocarvões ativados com cloreto de zinco $\left(\mathrm{ZnCl}_{2}\right)$ e $\mathrm{H}_{3} \mathrm{PO}_{4}$, verificaram que o material preparado com o ácido apresentou maior volume de mesoporos, independentemente da proporção biocarvão/agente ativante utilizada.

$\mathrm{Na}$ Figura 2, são apresentadas fotomicrografias obtidas na análise de MEV do BCA. Observa-se que o material apresentou uma morfologia irregular por toda sua superfície, exibindo estrutura porosa com poros de tamanhos e formas distintas, conforme resultados obtidos na análise de adsorção e dessorção de $\mathrm{N}_{2}$ (Figura 1A), e semelhantes a resultados obtidos por Nascimento et al. (2017).

A Figura 3 exibe os resultados das medidas de DRX para o BCA. Observa-se formação típica de estrutura de carbonos dispostos aleatoriamente, apresentando banda larga em torno de $2 \theta=20$ a $30^{\circ}$, correspondente à reflexão da estrutura micrografítica desordenada, característica dos carvões ativados (ALVES et al., 2019).

Os espectros de FTIR do BCA antes e após o processo de adsorção de GLF estão apresentados na Figura 4. Todas as interpretações dos picos basearam-se em estudos pregressos apresentados na literatura.

Conforme observado na Figura 4, foi possível detectar pico de absorção no comprimento de onda em torno de $3.400 \mathrm{~cm}^{-1}\left(3.385 \mathrm{~cm}^{-1}\right)$. De acordo com Herath et al. (2016), bandas largas próximas a $3.400 \mathrm{~cm}^{-1}$ podem ser atribuídas a vibrações de deformação axial -OH, provavelmente de grupos funcionais alcoólicos, fenólicos ou carboxílicos presentes na superfície do BCA. Picos de absorção no BCA após a adsorção do glifosato próximo a $1.700 \mathrm{~cm}^{-1}\left(1.695 \mathrm{~cm}^{-1}\right)$ podem ser atribuídos à presença de uma ligação C-O-P (HERATH et al., 2016; SEN; DATTA; MONDAL, 2019).

O pico próximo a $1.384 \mathrm{~cm}^{-1}\left(1.352 \mathrm{~cm}^{-1}\right)$ no $\mathrm{BCA}$, após adsorção do glifosato, poderia ser em razão de vibrações de deformação axial C-N de novas ligações formadas, enquanto picos entre 1.550 e $1.800 \mathrm{~cm}^{-1}\left(1.570 \mathrm{~cm}^{-1}\right)$ estão associados ao estiramento $\mathrm{C}=\mathrm{O}$ de carbonilas e ácidos carboxílicos (HERATH et al., 2016). Os picos observados entre 900 e $690 \mathrm{~cm}^{-1}\left(877,816\right.$ e $\left.754 \mathrm{~cm}^{-1}\right)$ podem estar associados à deformação angular C-H fora do plano (STUART, 2004).

Com relação à aparente baixa intensidade dos picos, Daifullah e Girgis (2003), ao verificarem o mesmo fenômeno, explicaram que o fato pode ser atribuído à maior área superficial do biocarvão, que reduz, consideravelmente, a densidade superficial dos grupos funcionais.

\section{Efeito do $\mathrm{pH}$ inicial}

Nas Figuras 5A e 5B, são apresentadas, respectivamente, a \%R e a $q_{\text {eq }}$ de GLF em função do $\mathrm{pH}$ do meio.

A remoção, assim como a $q_{\text {eq }}$ de GLF pelo BCA, apresentaram comportamentos semelhantes, marcados por baixo desempenho em $\mathrm{pH}$ extremamente ácido, seguido por aumento contínuo até o máximo de adsorção em pH 7, e, depois, exibindo diminuição significativa em $\mathrm{pH}$ alcalino. Esses dados demonstram que a adsorção de GLF foi dependente do $\mathrm{pH}$ da solução, uma vez que esse prâmetro afeta a carga superficial do adsorvente, bem como o grau de ionização e especiação da molécula de GLF (YAMAGUCHI; RUBIO; BERGAMASCO, 2019).

Tendo observado que a adsorção máxima de GLF ocorreu em pH 7, no qual o GLF apresenta três dissociações (alta densidade de cargas negativas), e que neste valor a superfície do adsorvente se apresenta positivamente carregada $(\mathrm{pH}$ $<\mathrm{pH}_{\mathrm{PCZ}}$ ), acredita-se que a adsorção do GLF sobre a superfície do BCA tenha ocorrido por meio de interações eletrostáticas. Por outro lado, quando o $\mathrm{pH}$ da solução aumentou $\left(\mathrm{pH}>\mathrm{pH}_{\mathrm{PCZ}}\right.$ ), a densidade de cargas superficiais positivas no BCA diminuiu, resultando em diminuição na adsorção de GLF em razão da força repulsiva entre adsorvente e as cargas negativas do GLF.

\section{Efeito da massa/dosagem de adsorvente}

Nas Figuras 6A e 6B, são apresentadas, respectivamente, a \%R e a $\mathrm{q}_{\mathrm{eq}}$ de GLF, ambas em função da massa de BCA.

O BCA apresentou máxima \%R $(62,67 \%)$ para massa igual a $0,5 \mathrm{~g}$ (equivalente a 10 g.L-1 ${ }^{-1}$. No entanto, quando os dados são avaliados em função da relação GLF removido/massa de BCA, verifica-se que a maior remoção $\left(\mathrm{q}_{\mathrm{eq}}=1,24 \mathrm{mg} \cdot \mathrm{g}^{-1}\right)$ ocorreu quando se adotou $0,25 \mathrm{~g}$ de BCA $\left(5,0 \mathrm{~g} . \mathrm{L}^{-1}\right)$. Isso demonstra que, ao dobrar a massa de BCA, não houve remoção proporcional. Também foi possível verificar que massas superiores a $0,5 \mathrm{~g}$ (833 mg BCA : $1 \mathrm{mg}$ de GLF) causaram a diminuição da \%R e da $\mathrm{q}_{\mathrm{eq}}$. 

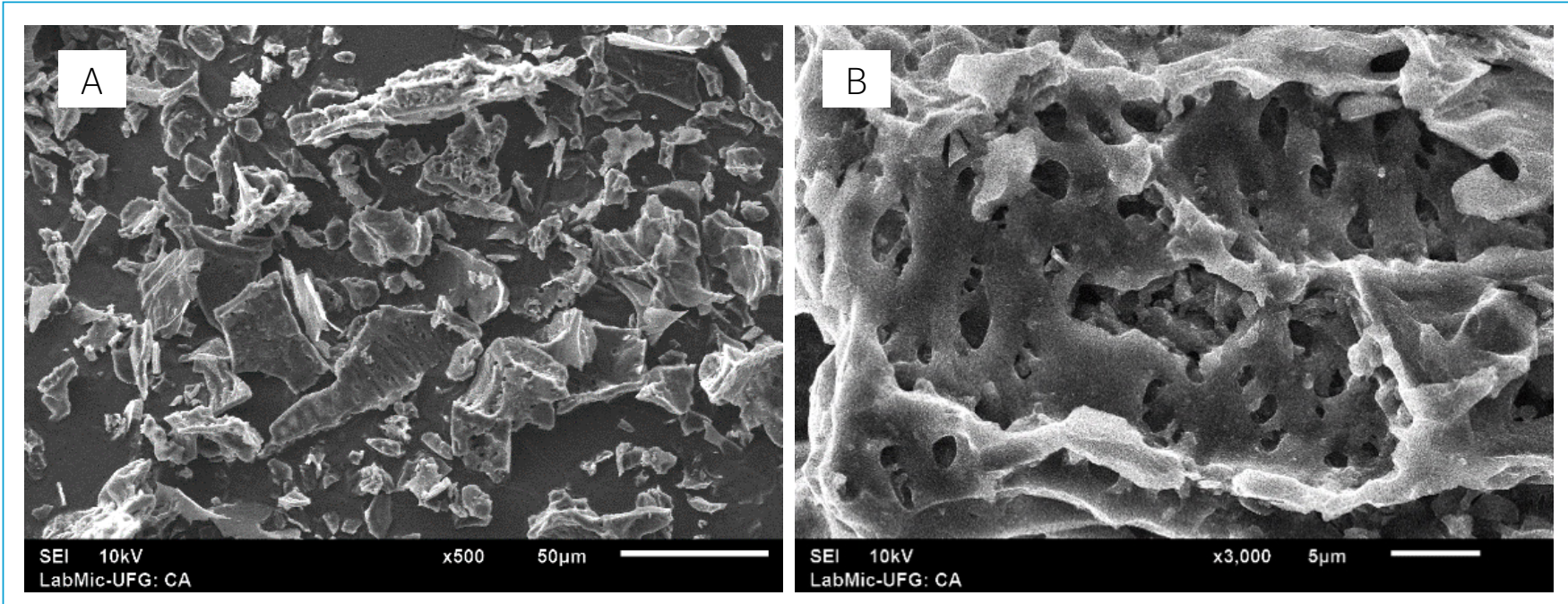

Fonte: os autores.

Figura 2 - Fotomicrografias das amostras de biocarvão de sabugo de milho ativado com ácido fosfórico: (A) ampliação de 500 vezes; (B) ampliação de 3.000 vezes.

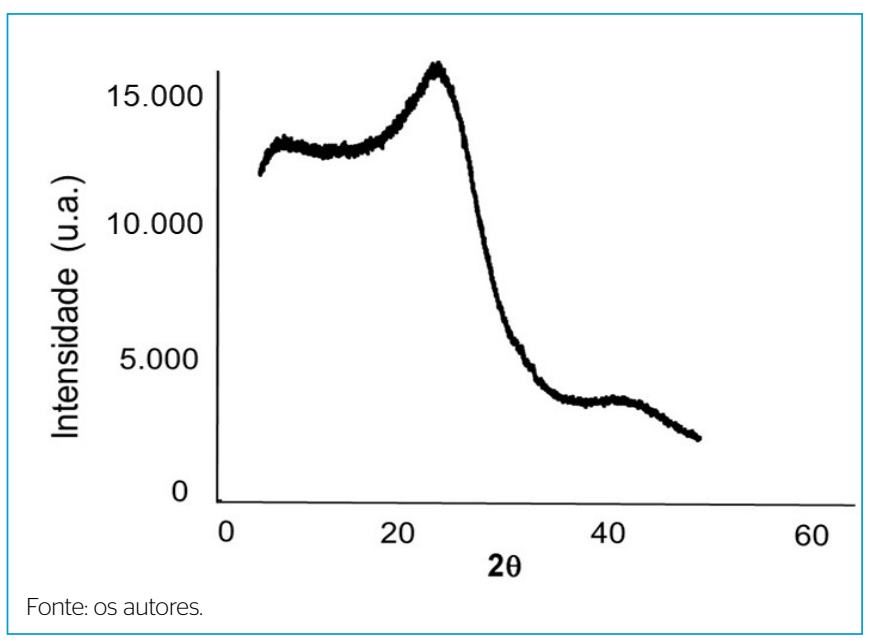

Figura 3 - Difratograma de raios $X$ do biocarvão de sabugo de milho ativado com ácido fosfórico.

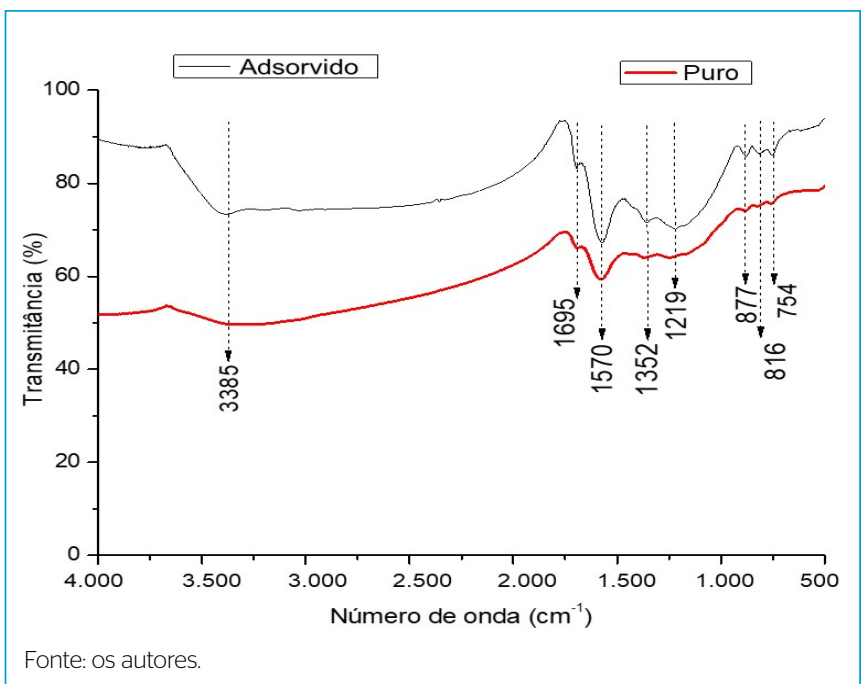

Figura 4 - Espectro de Infravermelho do biocarvão de sabugo de milho ativado com ácido fosfórico.
Sabe-se que o aumento da eficiência de remoção de GLF em relação à massa (dosagem) de adsorvente utilizada acontece em razão do aumento da área de superfície disponível para adsorção; porém, após determinada massa (dose) de adsorvente, o acréscimo não promoverá o aumento da adsorção, em razão da interferência entre os locais de ligação do adsorvente (KUMAR et al., 2014), justificando assim a diminuição na remoção em massas superiores a $0,5 \mathrm{~g}$.

\section{Cinética de adsorção}

O efeito do tempo de contato na adsorção de GLF pelo BCA foi avaliado, variando-se o tempo de contato BCA-GLF em intervalos de tempo predeterminados $(0,5,15,30,60,120,180$ e $240 \mathrm{~min})$, perfazendo um total de $4 \mathrm{~h}$ de ensaio. A relação entre a $\mathrm{q}_{\mathrm{eq}}$ de GLF e o tempo de contato, até que o sistema atinjisse o equilíbrio, encontra-se na Figura 7.

A partir dos dados apresentados na Figura 7, observa-se que o equilíbrio de adsorção foi atingido em aproximadamente $60 \mathrm{~min}$ de ensaio, considerado relativamente rápido quando comparado com outros resultados apresentados na literatura (Tabela 2). A máxima $\mathrm{q}_{\mathrm{eq}}$ foi de $1,49 \mathrm{mg} \cdot \mathrm{g}^{-1}$, e nos primeiros $15 \mathrm{~min}$, foi atingida $93 \%$ de sua capacidade máxima de adsorção.

Os dados cinéticos foram ajustados aos modelos de pseudoprimeira ordem e pseudossegunda ordem, na forma não linearizada, para se obter maiores informações sobre o comportamento de adsorção entre o GLF-BCA e a eficiência do processo de adsorção.

Nas Figuras 8A e 8B, são apresentados os dados experimentais e as curvas ajustadas aos modelos de pseudoprimeira ordem e pseudossegunda ordem, respectivamente. Na Tabela 2, são apresentados os parâmetros cinéticos de adsorção obtidos a partir das curvas de ajuste, bem como a quantidade de GLF adsorvida pelo BCA, calculada experimentalmente, e os $\mathrm{R}^{2}$.

A partir dos dados apresentados na Tabela 3, percebe-se que o modelo de pseudossegunda ordem foi o que melhor se ajustou aos dados experimentais $\left(\mathrm{R}^{2}=0,9987\right.$ e capacidade de adsorção calculada $\left.-\mathrm{q}_{\text {eqcal }}=1,3781\right)$. De acordo com Mayakaduwa et al. (2016), esse modelo sugere mecanismo de quimissorção que envolve a troca de elétrons entre adsorvato e adsorvente. Ainda, nesse 

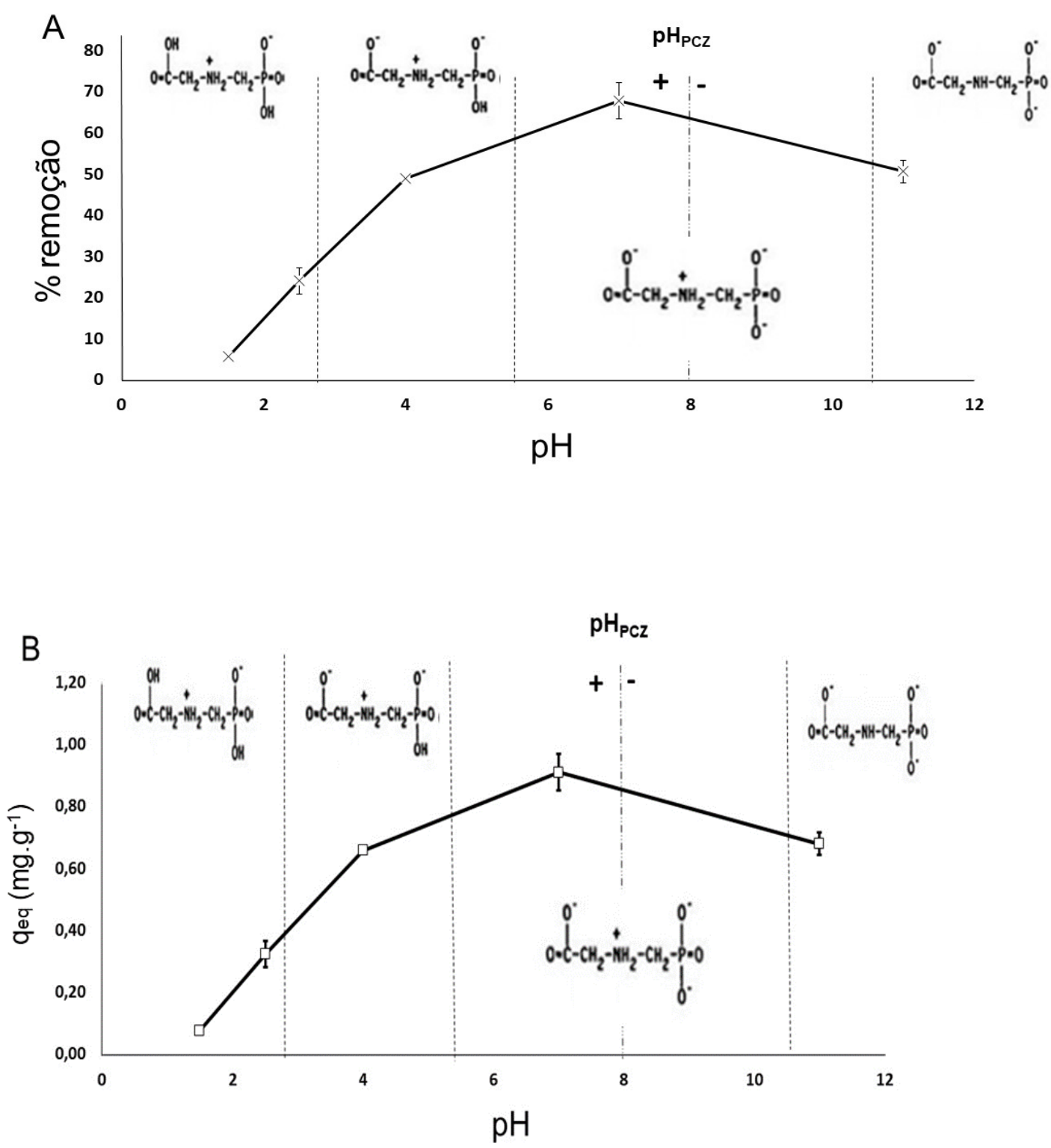

$\mathrm{pH}_{\mathrm{PCZ}}$ : ponto de carga zero; $\mathrm{q}_{\mathrm{eq}}$ : capacidade de adsorção.

*Agitação orbital de $120 \mathrm{rpm}$; ensaio com duração de $24 \mathrm{~h} ; \mathrm{C}_{0}=12 \mathrm{mg} . \mathrm{L}^{-1}$; razão massa $(\mathrm{mg})$ e volume $(\mathrm{mL})$ de $10 \mathrm{mg}: 1 \mathrm{~mL}(0,5 \mathrm{~g})$ (massa de adsorvente/volume da solução); $50 \mathrm{~mL}$ de solução; temperatura de $23^{\circ} \mathrm{C}$; triplicata.

Fonte: os autores.

Figura 5 - (A) Remoção de glifosato em função e (B) capacidade de adsorção de glifosato em função do pH*.

processo, as moléculas de GLF não são atraídas por todos os pontos do BCA, mas especificamente para os centros ativos, de maneira a formar uma monocamada. Essa hipótese é reforçada pelo fato de o experimento cinético ter sido conduzido em $\mathrm{pH}=7$, no qual, conforme mencionado, as moléculas de GLF apresentam alta densidade de cargas negativas em razão da predominância de suas formas dissociadas e de a superfície do adsorvente estar positivamente carregada em função de seu $\mathrm{pH}_{\mathrm{PCZ}}=8$.

Estudos de adsorção de GLF realizados por Sen, Datta e Mondal (2019) e Yamaguchi, Rubio e Bergamasco (2019) também apresentaram melhores ajustes ao modelo de pseudossegunda ordem.

\section{Isotermas de adsorção}

Na Figura 9, são apresentadas as isotermas de adsorção para os dados experimentais, relacionando a quantidade de GLF adsorvida no equilíbrio $\left(\mathrm{q}_{\mathrm{eq}}\right)$ e a concentração de equilíbrio de GLF na fase líquida às temperaturas de 23,43 e $63^{\circ} \mathrm{C}$ em $240 \mathrm{~min}$.

Observa-se, na Figura 9, que o BCA apresentou um mecanismo de adsorção com tendência linear à medida que a temperatura aumenta - nesse caso, a massa de GLF retida no BCA torna-se proporcional à concentração de equilíbrio do GLF na fase líquida (ALVES et al., 2019).

As isotermas obtidas a partir dos dados experimentais de equilíbrio para as três temperaturas foram ajustadas aplicando os modelos de Freundlich e 
A 70

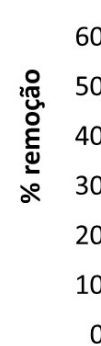

62,67

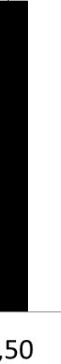

B

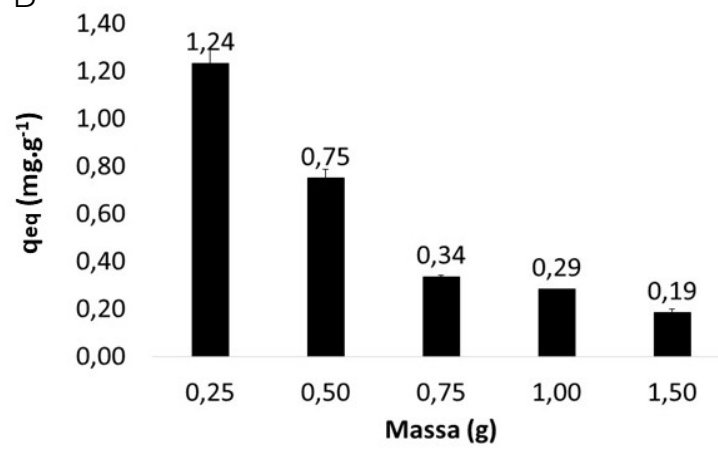

$\mathrm{q}_{\mathrm{eq}}$ : capacidade de adsorção.

*Agitação orbital de 120 rpm; ensaio com duração de 24 h; $C_{0}=12$ mg.L'-1 pH = 7; variação da razão massa de biocarvão de sabugo de milho ativado com ácido fosfórico (mg) e massa de glifosato (mg), presentes na solução (416:1, $833: 1,1250: 1,1666: 1,2500: 1) ; 50 \mathrm{~mL}$ de solução; temperatura de $23^{\circ} \mathrm{C}$; triplicata.

Fonte: os autores.

Figura 6 - (A) Remoção de glifosato e (B) capacidade de adsorção de glifosato em função da massa de biocarvão de sabugo de milho ativado com ácido fosfórico*.

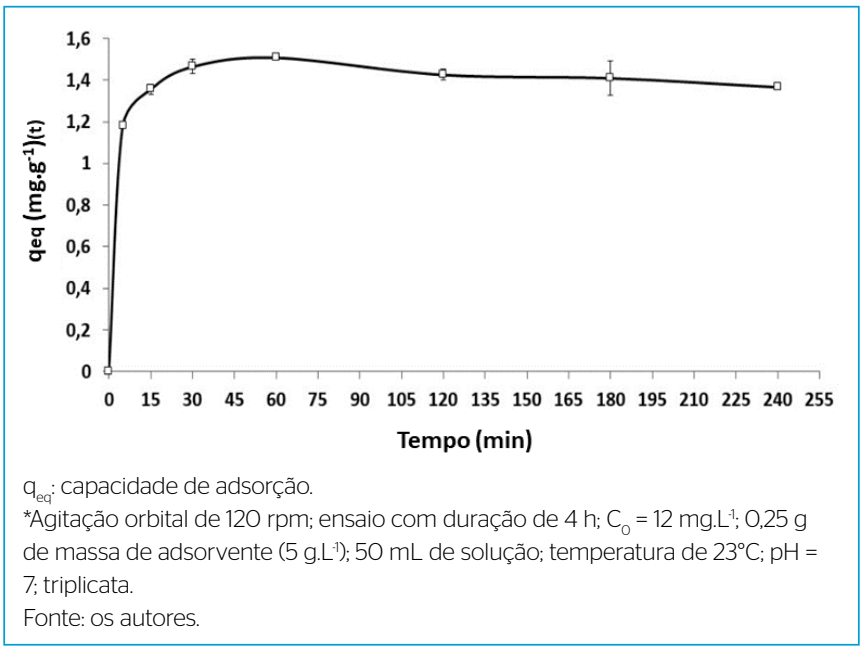

Figura 7 - Capacidade de adsorção de glifosato em função do tempo de contato*.

Tabela 2 - Comparação do tempo de equilíbrio na adsorção de glifosato para vários carvões ativados.

\begin{tabular}{|c|c|c|}
\hline Adsorvente & Tempo de equilibrio & Referência \\
\hline BCA de sabugo de milho & 1 hora & Presente estudo \\
\hline $\begin{array}{l}\text { CA comercial impregnado } \\
\text { com Fe e Mn }\end{array}$ & 24 horas & $\begin{array}{l}\text { Yamaguchi, Rubio e } \\
\text { Bergamasco (2019) }\end{array}$ \\
\hline BCA da casca de eucalipto & 2 horas & Sen, Datta e Mondal (2019) \\
\hline BC da casca de arroz & 1,5 hora & Herath et al. (2016) \\
\hline CA de folhas de palma & 4 horas & $\begin{array}{l}\text { Salman, Abid e } \\
\text { Muhammed (2012) }\end{array}$ \\
\hline $\begin{array}{l}\text { CA resíduo do tratamento } \\
\text { de água }\end{array}$ & 20 horas & Hu et al. (2011) \\
\hline $\begin{array}{l}\text { CA de jornal de } \\
\text { desperdício }\end{array}$ & 3 dias & $\begin{array}{c}\text { Nourouzi, Chuah e Choong } \\
\text { (2010) }\end{array}$ \\
\hline
\end{tabular}

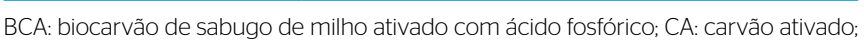
BC: biocarvão.

Fonte: elaborada pelos autores.
Langmuir na sua forma linearizada (Figura 10), e os parâmetros $\mathrm{q}_{\text {máx }}, \mathrm{K}_{\mathrm{L}}, \mathrm{K}_{\mathrm{P}}, n$ e $\mathrm{R}_{\mathrm{L}}$ foram calculados e apresentados na Tabela 4.

Nota-se que, para temperatura de $23^{\circ} \mathrm{C}$, a isoterma de adsorção foi melhor ajustada ao modelo de Freundlich $\left(\mathrm{R}^{2}=0,93\right)$, caracterizando uma adsorção de caráter físico que ocorre em superfície heterogênea com interações entre moléculas adsorvidas (CHOWDHURY et al., 2011). Porém, com o aumento da temperatura, verifica-se que os resultados se ajustam a ambos os modelos (valores de $\mathrm{R}^{2}$ semelhantes), ou seja, a maiores temperaturas, a adsorção do GLF sobre o BCA é governada tanto por mecanismos de quimissorção quanto de fisissorção.

O mecanismo de fisissorção pressupõe que a adsorção do GLF ocorre em multicamadas sobre uma superficie heterogênea no adsorvente, tendo diferentes energias de adsorção (HERATH et al., 2016). Embora os conceitos de quimissorção e fisissorção sejam distintos, os mecanismos de adsorção não são completamente independentes. A diferenciação quanto uma molécula ser fisicamente ou quimicamente adsorvida não é totalmente palpável (ALVES et al., 2019).

A $\mathrm{q}_{\text {máx }}$ apresentada pelo BCA $\left(2,67 \mathrm{mg} \cdot \mathrm{g}^{-1} / 63^{\circ} \mathrm{C}\right)$, foi relativamente baixa quando comparada com valores apresentados na literatura. Na Tabela 5, é apresentada a $\mathrm{q}_{\mathrm{eq}}$ máxima de GLF obtida para diferentes adsorventes, bem como sua classificação quanto a porosidade para fins comparativos.

A baixa quantidade de GLF adsorvido pelo BCA de sabugo de milho produzido para o presente estudo pode ser atribuída à sua característica mesoporosa, visto que os estudos que obtiveram desempenho elevado apresentaram material adsorvente com estrutura microporosa (DADA et al., 2012).

Ainda, com relação aos valores de $\mathrm{q}_{\text {máx }}$ obtidos no presente estudo, é preciso salientar que os dados de adorção foram obtidos a partir de ensaios realizados com solução comercial de glifosato, em cuja composição tem-se surfactantes que podem vir a competir com os sítios ativos de adsorção, diminuindo assim a $\mathrm{q}_{\mathrm{eq}}$ do GLF.

Com relação ao parâmetro $n$ de Freundlich para o BCA, este apresentou, em todas as temperaturas, valor entre 1 e 10, indicando adsorção favorável, ou seja, existe forte interação entre o GLF e o BCA (MCCABE; SMITH; HARRIOT, 1993). Essa forte interação GLF-BCA também pode ser comprovada por meio de $\mathrm{R}_{\mathrm{L}}$ (fator de separação de Langmuir), cujos valores calculados permaneceram entre 0 e 1 , indicando que o adsorvato (GLF) apresenta maior afinidade 


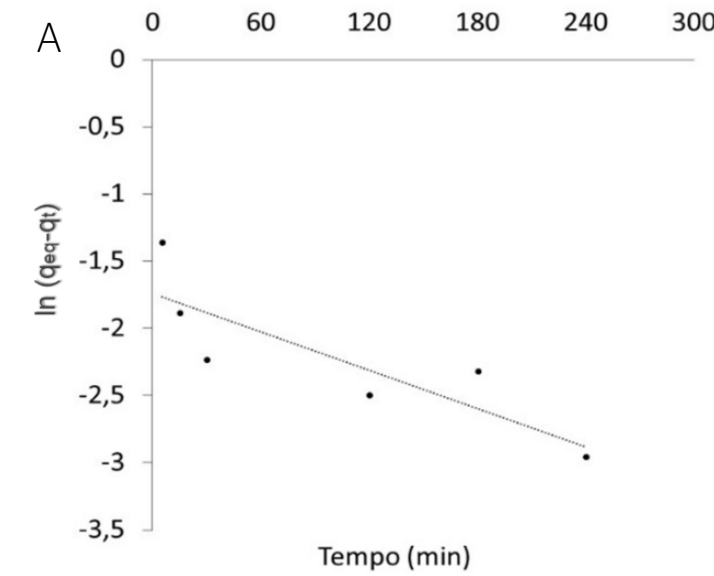

$\mathrm{B}$

In: logaritmo natural; $\mathrm{q}_{\mathrm{eq}}$ : quantidade adsorvida por grama de adsorvente no equilíbrio; $\mathrm{q}_{\mathrm{t}}$ quantidade adsorvida por grama de adsorvente no tempo t; t: tempo. Fonte: os autores.

Figura 8 - Ajuste linear aos modelos de (A) pseudoprimeira e (B) pseudossegunda ordem.

Tabela 3 - Parâmetros cinéticos calculados a partir dos ajustes dos modelos linearizados de pseudoprimeira ordem e de pseudossegunda ordem aos dados experimentais.

\begin{tabular}{l|c|c|c}
\hline Adsorvente & $\mathrm{q}_{\text {eqexp }}$ & $\begin{array}{c}\text { Pseudoprimeira } \\
\text { ordem }\end{array}$ & $\begin{array}{c}\text { Pseudossegunda } \\
\text { ordem }\end{array}$ \\
$\begin{array}{l}\text { BCA de sabugo } \\
\text { de milho }\end{array}$ & 1,49 & $\begin{array}{c}\mathrm{q}_{\text {eqcal }}=1,249 \\
\mathrm{k}_{1}=0,467 \\
\mathrm{R}^{2}=0,8164\end{array}$ & $\begin{array}{c}\mathrm{q}_{\text {eqcal }}=1,3781 \\
\mathrm{k}_{2}=0,4184 \\
\mathrm{R}^{2}=0,9987\end{array}$ \\
\hline
\end{tabular}

$\mathrm{q}_{\text {eqexp: }}$ : capacidade de adsorção experimental; BCA: biocarvão de sabugo de milho ativado com ácido fosfórico; $\mathrm{q}_{\mathrm{eccal}}$ capacidade de adsorção calculada; $\mathrm{k}_{\mathrm{i}}$ constante da taxa de adsorção de pseudoprimeira ordem ( min $\left.^{-1}\right)$; $\mathrm{R}^{2}$ : coeficiente de determinação; $k_{2}$ : constante da taxa de adsorção de pseudossegunda ordem (g.mg'! $\left.\min ^{-1}\right) ; \mathrm{q}=\mathrm{mg} \cdot \mathrm{g}^{-1}$.

Fonte: elaborada pelos autores.

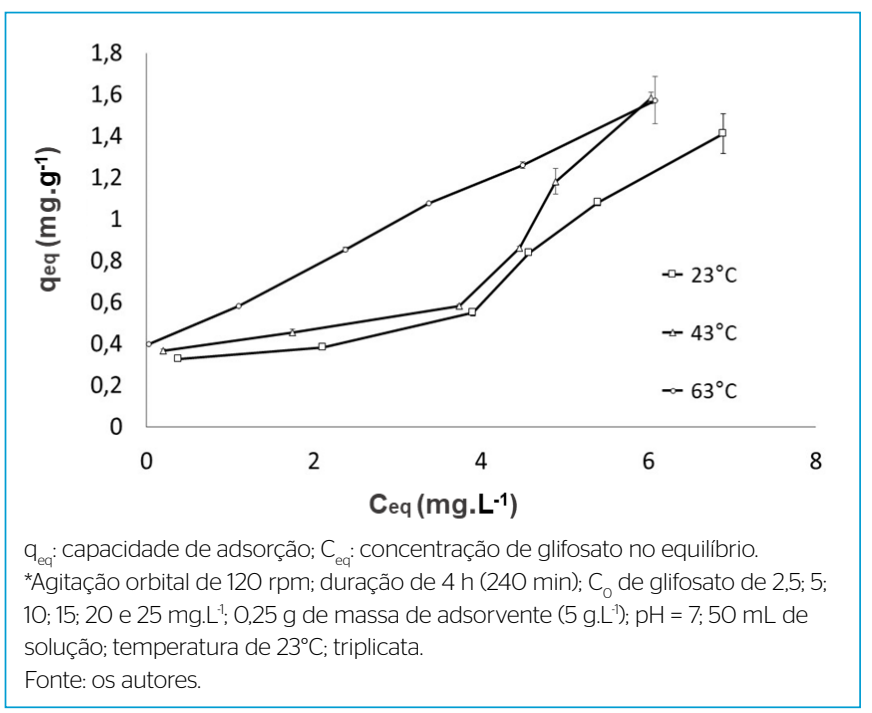

Figura 9 - Isotermas de adsorção para os dados experimentais nas temperaturas de 23,43 e $63^{\circ} \mathrm{C}^{*}$. com a fase sólida do que com a líquida. Assim, a adsorção é considerada favorável (MAYAKADUWA et al., 2016).

\section{Estudo termodinâmico de adsorção}

A temperatura é um parâmetro muito importante do ponto de vista operacional, que influencia diretamente no processo de adsorção (MONDAL; ROY, 2018). Neste estudo, os valores das propriedades termodinâmicas $\Delta \mathrm{G}^{\circ}, \Delta \mathrm{H}^{\circ} \mathrm{e}$ $\Delta S^{\circ}$ foram calculados a partir das isotermas de adsorção de GLF a $23 \pm 2^{\circ} \mathrm{C}$, $43 \pm 2^{\circ} \mathrm{C}$ e $63 \pm 2^{\circ} \mathrm{C}$. Os dados estão apresentados na Tabela 6 .

Os dados apresentados na Tabela 6 demonstram que a adsorção de GLF no BCA de sabugo de milho produzido é um processo endotérmico em razão do valor positivo de $\Delta \mathrm{H}^{\circ}$. Essa condição também pode ser corroborada ao analisar os valores de $\mathrm{q}_{\text {max }}$ obtidos pelo modelo de Langmuir para a temperatura de $63^{\circ} \mathrm{C}\left(2,67 \mathrm{mg} \cdot \mathrm{g}^{-1}\right)$, que foram, aproximadamente, 2,6 vezes maiores que o valor obtido para a temperatura de $43^{\circ} \mathrm{C}\left(1,02 \mathrm{mg} \cdot \mathrm{g}^{-1}\right)$. Esse aumento na $\mathrm{q}_{\mathrm{eq}}$ pode ocorrer em razão da interação química entre adsorbato e adsorvente, da criação de alguns novos locais de adsorção ou do aumento da taxa de difusão intrapartículas de moléculas de GLF nos poros do BCA a temperaturas mais altas (TAN; AHMAD; HAMEED, 2008). E as maiores taxas de difusão das moléculas de adsorvato por meio da superfície externa e nos poros internos do adsorvente ocorrem em razão do decréscimo da viscosidade da solução e da mudança das relações de equilíbrio (FAN et al., 2012).

O valor calculado para a $\Delta \mathrm{G}^{\circ}$ de $21,7 \mathrm{~kJ} \cdot \mathrm{mol}^{-1}$ não se enquadra nas faixas de valores de $\Delta \mathrm{H}^{\circ}$ correspondentes aos mecanismos de fisissorção (5-10 kJ.mol $\left.{ }^{-1}\right) \mathrm{e}$ quimissorção $\left(30-40 \mathrm{~kJ} \cdot \mathrm{mol}^{-1}\right)$, reforçando a hipótese de que o mecanismo de adsorção do GLF no BCA produzido não é totalmente químico, nem totalmente físico, e que, na verdade, a adsorção ocorre por mecanismos mais complexos (LI et al., 2011; YAMAGUCHI; RUBIO; BERGAMASCO, 2019).

$\mathrm{O}$ valor positivo de $\Delta \mathrm{S}^{\circ}$ indica maior afinidade existente entre o $\mathrm{BCA}$ e o GLF do que a afinidade entre BCA e fase líquida, assim como aumento da aleatoriedade na interface sólido-líquido durante o processo de adsorção (TAN; AHMAD; HAMEED, 2008). Ainda, como $\Delta \mathrm{G}^{\circ}>0$ e os valores de $\mathrm{K}_{\mathrm{D}}$ diminuem 
A

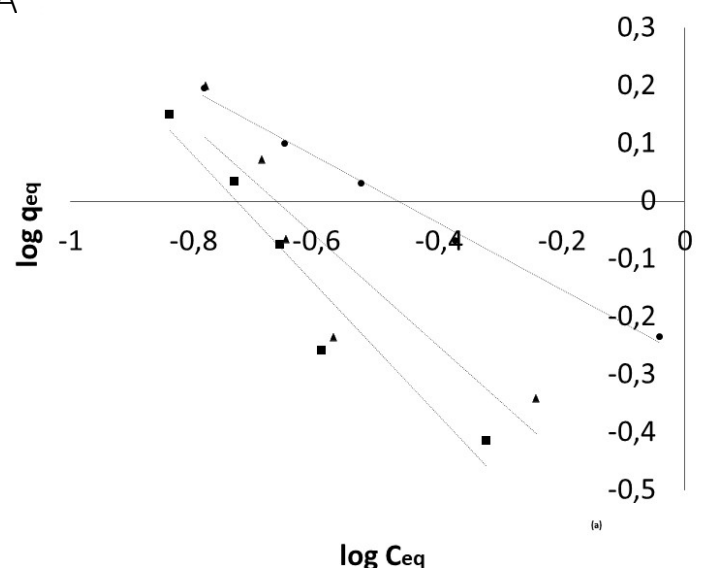

B

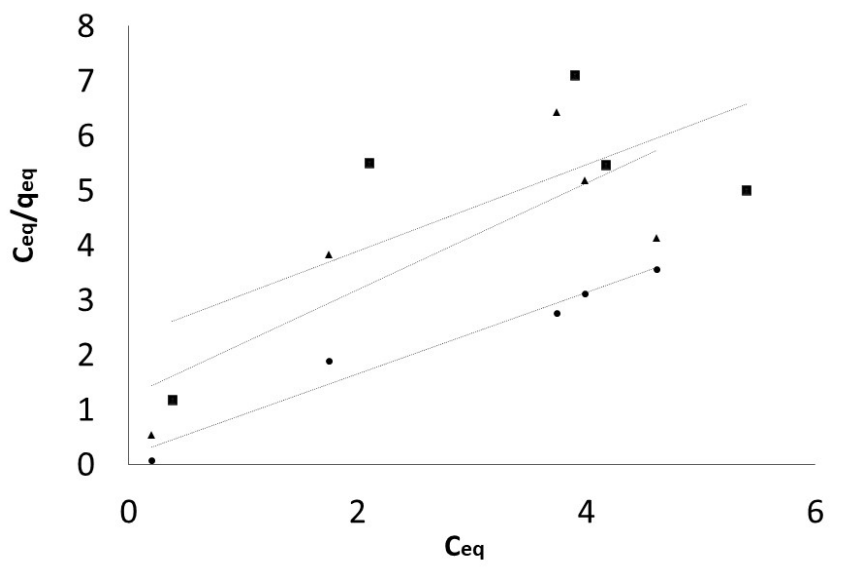

Nota: $\triangle 23^{\circ} \mathrm{C} ; 43^{\circ} \mathrm{C} ; 63^{\circ} \mathrm{C}$.

$\mathrm{q}_{\mathrm{eq}}$ : capacidade de adsorção; $\mathrm{C}_{\mathrm{eq}}$ : concentração de glifosato no equilíbrio. Fonte: Os autores.

Figura 10 - Ajustes das isotermas de adsorção na forma linearizada nas temperaturas de 23,43 e $63^{\circ} \mathrm{C}$, para os modelos de (A) Freundlich e (B) Langmuir.

Tabela 4 - Parâmetro das equações de Langmuir e Freundlich para a adsorção de glifosato para as temperaturas de 23,43 e $63^{\circ} \mathrm{C}$.

\begin{tabular}{|c|c|c|c|}
\hline Modelo isotérmico & Temperatura $\left({ }^{\circ} \mathrm{C}\right)$ & \multicolumn{2}{|c|}{ Parâmetros } \\
\hline \multirow{9}{*}{ Freundlich } & \multirow{3}{*}{23} & $\mathrm{~K}_{\mathrm{F}}$ & 3,79 \\
\hline & & $\mathrm{n}$ & 1,78 \\
\hline & & $R^{2}$ & 0,93 \\
\hline & \multirow{3}{*}{43} & $\mathrm{~K}_{\mathrm{F}}$ & 4,29 \\
\hline & & $n$ & 1,04 \\
\hline & & $R^{2}$ & 0,81 \\
\hline & \multirow{3}{*}{63} & $\mathrm{~K}_{\mathrm{F}}$ & 1,82 \\
\hline & & $\mathrm{n}$ & 1,73 \\
\hline & & $\mathrm{R}^{2}$ & 0,99 \\
\hline \multirow{12}{*}{ Langmuir } & \multirow{4}{*}{23} & $\mathrm{q}_{\text {máx }}$ & 1,26 \\
\hline & & $K_{L}$ & 0,3422 \\
\hline & & $R^{2}$ & 0,63 \\
\hline & & $\mathrm{RL}$ & 0,69 \\
\hline & \multirow{4}{*}{43} & $\mathrm{q}_{\text {máx }}$ & 1,02 \\
\hline & & $\mathrm{K}_{\mathrm{L}}$ & 0,2961 \\
\hline & & $\mathrm{R}^{2}$ & 0,89 \\
\hline & & $\mathrm{RL}$ & 0,91 \\
\hline & \multirow{4}{*}{63} & $\mathrm{q}_{\text {máx }}$ & 2,67 \\
\hline & & $\mathrm{K}_{\mathrm{L}}$ & 0,6745 \\
\hline & & $\mathrm{R}^{2}$ & 0,96 \\
\hline & & $\mathrm{RL}$ & 0,30 \\
\hline
\end{tabular}

$\mathrm{K}_{\mathrm{F}}$ : constante de Freundlich relacionada à capacidade de adsorção $\left(\mathrm{mg}^{-1} \mathrm{~g}^{-1}\right)\left(\mathrm{mg} \cdot \mathrm{L}^{-1}\right) 1 / \mathrm{n}$; $n$ : constante de Freundlich relacionada à intensidade de adsorção; $\mathrm{R}^{2}$ : coeficiente de determinação; $q_{\text {máx: }}$ número total de sítios disponíveis no material adsorvente (capacidade de adsorção máxima) ( $\left.\mathrm{mg}^{-1} \mathrm{~g}^{-1}\right) ; \mathrm{K}_{\llcorner}$: constante de interação entre o adsorvido e o adsorvente ( $L . \mathrm{mg}^{-1}$ ); $\mathrm{R}_{\mathrm{L}}$ : fator de separação, calculado considerando-se $\mathrm{C}_{0}$ de $2,5 \mathrm{mg} \mathrm{L-1}$

Fonte: elaborada pelos autores.
Tabela 5 - Comparação da capacidade máxima de adsorção de glifosato para diferentes adsorventes associados à sua classificação quanto à porosidade.

\begin{tabular}{|c|c|c|}
\hline Adsorvente & $\mathrm{q}_{\text {máx }}$ & Referência \\
\hline $\begin{array}{l}\text { CA comercial } \\
\text { impregnado com Fe } \\
\text { e Mn }\end{array}$ & 9,19 mg.g $\mathrm{g}^{-1}$ (mesoporoso) & $\begin{array}{l}\text { Yamaguchi, Rubio e } \\
\text { Bergamasco (2019) }\end{array}$ \\
\hline CA da casca de eucalipto & $\begin{array}{c}66,76 \text { mg.g } \\
\text { (microporoso) }\end{array}$ & $\begin{array}{c}\text { Sen, Datta e Mondal } \\
\text { (2019) }\end{array}$ \\
\hline $\begin{array}{l}\text { CA funcionalizado com } \\
\text { óxido de grafeno }\end{array}$ & $3,7 \mathrm{mg} \mathrm{g}^{-1}$ (mesoporoso) & Marin et al. (2019) \\
\hline BC da casca de arroz & $123 \mathrm{mg} \mathrm{g}^{-1}$ (microporoso) & Herath et al. (2016) \\
\hline $\begin{array}{l}\mathrm{BC} \text { de resíduo de } \\
\text { indústria de bioenergia }\end{array}$ & $44 \mathrm{mg}^{-1}$ (microporoso) & Mayakaduwa et al. (2016) \\
\hline $\begin{array}{l}\text { CA de jornal de } \\
\text { desperdício }\end{array}$ & $48 \mathrm{mg} \mathrm{g}^{-1}$ (microporoso) & $\begin{array}{l}\text { Nourouzi, Chuah e } \\
\text { Choong (2010) }\end{array}$ \\
\hline BCA de sabugo de milho & 2,67 mg.g (mesoporoso) & Presente estudo \\
\hline
\end{tabular}

$\mathrm{q}_{\text {máx: }}$ : número total de sítios disponíveis no material adsorvente (capacidade de adsorção máxima); CA: carvão ativado; BC: biocarvão; BCA: biocarvão de sabugo de milho ativado com ácido fosfórico.

Fonte: elaborada pelos autores.

Tabela 6 - Parâmetros termodinâmicos para a adsorção de GLF.

\begin{tabular}{|c|c|c|c|c|}
\hline \multicolumn{5}{|c|}{ Parâmetros termodinâmicos } \\
\hline $\mathrm{T}\left({ }^{\circ} \mathrm{C}\right)$ & $\mathrm{K}_{\mathrm{D}}$ & $\begin{array}{c}\Delta \mathrm{G}^{\circ} \\
\left(\mathrm{KJ} \cdot \mathrm{mol}^{-1}\right)\end{array}$ & $\begin{array}{c}\Delta \mathrm{H}^{\mathrm{O}} \\
\left(\mathrm{KJ} \cdot \mathrm{mol}^{-1}\right)\end{array}$ & $\begin{array}{c}\Delta \mathrm{SO}^{\circ} \\
\left(\mathrm{KJ} . \mathrm{mol}^{-1} \mathrm{~K}\right)\end{array}$ \\
\hline 23 & 0,177 & 4,25 & \multirow{3}{*}{21,7} & \multirow{3}{*}{0,06} \\
\hline 43 & 0,120 & 5,58 & & \\
\hline 63 & 0,077 & 7,16 & & \\
\hline
\end{tabular}

T: temperatura; $\mathrm{K}_{\mathrm{D}}$ : constante de equilíbrio termodinâmico; $\Delta \mathrm{GO}$ : energia livre de Gibs; $\Delta \mathrm{H}^{\mathrm{O}}$ : variação da entalpia; $\Delta \mathrm{SO}$ : variação da entropia. Fonte: elaborada pelos autores. 
com o aumento da temperatura, o processo pode ser caracterizado como uma adsorção endergônica, ou seja, a adsorção não é espontânea, sugerindo que há a presença de barreiras energéticas no processo, de forma que, nesse caso, o aumento da temperatura favorece a superação delas (ZHOU; LI; JIANG, 2014).

\section{CONCLUSÃO}

O presente estudo apresentou os resultados da adsorção de formulação comercial de GLF em BCA. Os resultados demonstraram que a adsorção foi altamente dependente do $\mathrm{pH}$ e da temperatura, sendo $\mathrm{pH}=7$ e temperatura de $63^{\circ} \mathrm{C}$ a condição mais favorável, apresentando capacidade máxima de adsorção de $2,67 \mathrm{mg} \cdot \mathrm{L}^{-1}$. Os resultados cinéticos demonstraram rápida adsorção do GLF no BCA, alcançando 98\% da capacidade máxima de adsorção em 15 min e o equilíbrio em 60 min.

Os dados cinéticos foram melhor ajustados ao modelo de pseudossegunda ordem, indicando predominância do mecanismo de quimissorção. Porém, os dados obtidos nos ensaios de isoterma indicam que o mecanismo de fisissorção também governa a adsorção, visto que tanto o modelo de Freundlich quanto o de Langmuir apresentaram $R^{2}$ elevados $\left(R^{2}>0,89\right)$.

Os valores das constantes termodinâmicas revelaram que a adsorção de GLF é de natureza endotérmica, favorecida com o aumento da temperatura $(\Delta \mathrm{H}>0)$, e endergônica $(\Delta \mathrm{G}>0)$, indicando que o processo de adsorção não é espontâneo, condições essas que podem comprometer a aplicação do BCA estudado no tratamento de águas contaminadas com GLF.

\section{CONTRIBUIÇÕES DOS AUTORES}

Marcelino, N.V.A.: Conceituação, Metodologia, Escrita — Primeira Redação, Escrita - Revisão e Edição. Cuba, R. M. F.: Conceituação, Supervisão, Escrita - Primeira Redação, Escrita - Revisão e Edição. Teran, F. J. C.: Conceituação, Escrita - Revisão e Edição.

\section{REFERÊNCIAS}

ALVES, A.C.; ANTERO, R.V.P.; OLIVEIRA, S.B.; OJALA, S.A.; SCALIZE, P.S. Activated carbon produced from waste coffee grounds for an effective removal of bisphenol-A in aqueous medium. Environmental Science and Pollution Research, v. 26, n. 24, p. 24850-24862, 2019. https://doi.org/10.1007/ s11356-019-05717-7

BARRETT, E.P.; JOYNER, L.G.; HALENDA, P.P. The Determination of Pore Volume and Area Distributions in Porous Substances. I. Computations from Nitrogen Isotherms. Journal of the American Chemical Society, v. 73, n. 1, p. 373-380, 1951. https://doi.org/10.1021/ja01145a126

BILA, D.M.; DEZOTTI, M. Desreguladores endócrinos no meio ambiente: efeitos e consequências. Química Nova, v. 30, n. 3, p. 651-666, 2007. https:// doi.org/10.1590/S0100-40422007000300027

BOMBARDI, L.M. Geografia do Uso de Agrotóxicos no Brasil e Conexões com a União Europeia. São Paulo: FFLCH / USP, 2017. 35 p.

BRASIL. Conselho Nacional do Meio Ambiente. Resolução no 357, de 17 de março de 2005. Brasil: Conselho Nacional do Meio Ambiente, 2005.

BRASIL. Ministério da Saúde. Portaria no 5, de 2017. Brasília: Ministério da Saúde, 2017

BRUNAUER, E.; EMMETT, P.H.; TELLER, E. Adsorption of Gases in Multimolecular Layers. Journal of the Chemical Society, v. 60, n. 2 , p. 309-319, 1938. https://doi.org/10.1021/jaO1269aO23

CASTRO, K.C.; COSSOLIN, A.S.; REIS, H.C.O.; MORAIS, E.B. Biosorption of anionic textile dyes from aqueous solution by yeast slurry from brewery. Brazilian Archives of Biology and Technology, v. 60, p. 1-13, 2017. https://doi. org/10.1590/1678-4324-2017160101

CHOWDHURY, S:; MISHRA, R.; SAHA, P.; KUSHWAHA, P. Termodinâmica de adsorção, cinética e calor isostérico da adsorção de verde malaquita em casca de arroz quimicamente modificada. Dessalinização, v. 265, p. 159-168, 2011.

COMPANHIA NACIONAL DE ABASTECIMENTO (CONAB). Safra de grãos 2019/2020 deve alcançar recorde de 251,9 milhões de toneladas. CONAB,
2020. Disponível em: https://www.gov.br/pt-br/hoticias/agricultura-epecuaria/2O2O/03/safra-de-graos-2019-2020-deve-alcancar-recorde-de251-9-milhoes-de-toneladas. Acesso em: 20 maio 2020.

COOK, M.M.; SYMONDS, E.M.; GERBER, B.; HOARE, A.; VAN VLEET, E.S.; BREITBART, M. Removal of six estrogenic endocrine-disrupting compounds (EDCs) from municipal wastewater using aluminum electroagulation. Water, v. 8, n. 4, p. 128, 2016. https://doi.org/10.3390/w8040128

CUI, H.; LI, Q.; QIAN, Y.; ZHANG, Q.; ZHAI, J. Desempenho na preparação e adsorção do compósito $\mathrm{MnO} 2$ / PAC em relação ao glifosato aquoso. Tecnologia Ambiental, v. 33, n. 16-18, p. 2049-2056, 2012.

DADA, A.O.; OLALEKAN, A.P.; OLATUNYA, A.M.; DADA, O. Langmuir, Freundlich, Temkin e Dubinin-Radushkevich Isotherms Studies of Equilibrium Sorption of Zn2+ Unto Phosphoric Acid Modified Rice Husk. IOSR Journal of Applied Chemistry, v. 3, n. 1, p. 38-45, 2012.

DAIFULLAH, A.A.M.; GIRGIS, B.S. Impact of surface characteristics of activated carbon on adsorption of BTEX. Colloids and Surfaces A: Physicochemical and Engineering Aspects, v. 214, n. 1-3, p. 181-193, 2003. https://doi.org/10.1016/S0927-7757(O2)00392-8

FAN, L.; LUO, C.; LI, X.; LU, F.; QIU, H.; SUN, M. Fabricação de nova quitosana magnética enxertada com óxido de grafeno para melhorar as propriedades de adsorção do azul de metila. Jornal de Materiais Perigosos, v. 215-216, p. 272-279, 2012. https://doi.org/10.1016/j.jhazmat.2012.02.068

GWENZI, W.; CHAUKURA, N.; NOUBACTEP, C.; MUKOME, F.N.D. Biochar-based water treatment systems as a potential low-cost and sustainable technology for clean water provision. Journal of Environmental Management, v. 197, p. 732-749, 2017. https://doi.org/10.1016/j.jenvman.2017.03.087

HEIDARI, A.; YOUNESI, H.; RASHIDI, A.; GHOREYSHI, A. Adsorptive removal of $\mathrm{CO} 2$ on highly microporous activated carbons prepared from Eucalyptus camaldulensis wood: effect of chemical activation. Journal of the Taiwan Institute of Chemical Engineers, v. 45, n. 2, p. 579-588, 2014. https://doi. org/10.1016/j.jtice.2013.06.007 
HERATH, G.A.D.; POH, L.S.; NG, W.J. Statistical optimization of glyphosate adsorption by biochar and activated carbon with response surface methodology. Chemosphere, v. 277, p. 533-540, 2019. https://doi.org/10.1016/j. chemosphere.2019.04.078

HERATH, I.; KUMARATHILAKA, P.; AL-WABEL, M.l; ABDULJABBAR, A.; AHMAD, M.; USMAN, A.R.A; VITHANAGE, M. Mechanistic modeling of glyphosate interaction with rice husk derived engineered biochar. Microporous and Mesoporous Materials, v. 225, p. 280-288, 2016. https://doi. org/10.1016/j.micromeso.2016.01.017

HO, Y.S.; MCKAY, G. A Comparison of Chemisorption Kinetic Models Applied to Pollutant Removal on Various Sorbents. Process Safety and Environmental Protection, v. 76, n. 4, p. 332-340, 1998. https://doi. org/10.1205/095758298529696

HU, Y.S.; ZHAO, Y.Q.; SOROHAN, B. Removal of glyphosate from aqueous environment by adsorption using water industrial residual. Desalination, v. 271, n. 1-3, p. 150-156, 2011. https://doi.org/10.1016/j.desal.2010.12.014

JARDIM, V. Aplicação de fungos de podridão branca na degradação de 4-nonilfenol, 4-octilfenol e bisfenol-A e avaliação da redução da atividade estrogênica pela linhagem celular MCF-7 bus. Tese (Doutorado) - Faculdade de Engenharia Civil, Arquitetura e Urbanismo, Universidade Estadual de Campinas, Campinas, 2017.

JIANG, X:; OUYANG, Z; ZHANG, Z:; YANG, C.; LI, X:; DANG, Z; WU, P. Mechanism of glyphosate removal by biochar supported nano-zerovalent iron in aqueous solutions. Colloids and Surfaces A: Physicochemical and Engineering Aspects, v. 547, p. 64-72, 2018. https://doi.org/10.1016/j. colsurfa.2018.03.041

KHOURY, G.A.; GEHRIS, T.C.; TRIBE, L.; TORRES SÁNCHEZ, R.M.; SANTOS AFONSO, M. Glyphosate adsorption on montmorillonite: An experimental and theoretical study of surface complexes. Applied Clay Science, v. 50, n. 2. p. 167-175, 2010. https://doi.org/10.1016/j.clay.2010.07.018

KUMAR, P.; SINGH, H.; KAPUR, M.; MONDAL, M.K. Comparative study of malathion removal from aqueous solution by agricultural and commercial adsorbents. Journal of Water Process Engineering, v. 3, p. 67-73, 2014. https://doi.org/10.1016/j.jwpe.2014.05.010

LAGERGREN, S. About the theory of so-called adsorption of soluble substances. Kungliga Svenska Vetenskapsakademiens Handlingar, v. 24, n. 4, p. 1-39, 1898.

LI, W.; YUE, Q.; GAO, B.; MA, Z:; LI, Y.; ZHAO, H. Preparation and utilization of sludgebased activated carbon for the adsorption of dyes from aqueous solutions. Chemical Engineering Journal, v. 171, n. 1, p. 320-327, 2011. https:// doi.org/10.1016/j.cej.2011.04.012

LOPES, C.W.; BERTELLA, F.; PERGHER, S.B.C.; FINGER, P.H.; DALLAGO, R.M; PENHA, F.G. Síntese e caracterização de carvões ativados derivados do sabugo de milho. Perspectiva, v. 37, n. 139, p. 27-35, 2013.

LU, H.; ZHANG, W.; YANG, Y.; HUANG, X.; WANG, S:; QIU, R. Relative distribution of $\mathrm{Pb} 2+$ sorption mechanisms by sludge derived biochar. Water Research, v. 46, n. 3, p. 854-862, 2012. https://doi.org/10.1016/j.watres.2011.11.058

MARIN, P.; BERGAMASCO, R.; MÓDENES, A.N.; PARAISO, P.R.; HAMOUDI, $S$. Synthesis and characterization of graphene oxide functionalized with MnFe2O4 and supported on activated carbon for glyphosate adsorption in fixed bed column. Process Safety and Environmental Protection, v. 123, p. 59-71, 2019. https://doi.org/10.1016/j.psep.2018.12.027
MARQUES, M.B.L.; AMÉRICO-PINHEIRO, J.H.P. Efeitos ecotoxicológicos de metais aos organismos aquáticos. Periódico Eletrônico Fórum Ambiental da Alta Paulista, v. 14, n. 4, 2018. http://dx.doi.org/10.17271/19800827144201 81952

MAYAKADUWA, S.S.; KUMARATHILAKA, P.; HERATH, I.; AHMAD, M.; ALWABEL, M.; OK, Y.S.; USMAN, A.; ABDULJABBAR, A.; VITHANAGE, M. Equilibrium and kinetic mechanisms of woody biochar on aqueous glyphosate removal. Chemosphere, v. 144, p. 2516-2521, 2016. https://doi. org/10.1016/j.chemosphere.2015.07.080

MCCABE, W.L.; SMITH, J.C.; HARRIOT, P. Units Operation of Chemical Engineering. 5. ed. Nova York: McGraw-Hill, 1993.

MONDAL, N.K.; GHOSH, P.; SEN, K., MONDAL, A.; DEBNATH, P. Efficacy of onion peel towards removal of nitrate from aqueous solution and field samples. Environmental Nanotechnology, Monitoring and Management, v. 11, 100222, 2019. https://doi.org/10.1016/j.enmm.2019.100222

MONDAL, N.K.; ROY, A. Potentiality of a fruit peel (banana peel) toward abatement of fluoride from synthetic and underground water samples collected from fluoride affected villages of Birbhum district. Applied Water Science, v. 8, p. 89-99, 2018. https://doi.org/10.1007/s13201-018-0729-3

NASCIMENTO, C.T. Estudo da adsorção de carbendazim em biocarvão ativado de palha de milho. In: CONGRESSO BRASILEIRO DE SISTEMAS PARTICULADOS, 38., 2017. Anais [...]. 2017.

NOUROUZI, M.M.; CHUAH, T.G.; CHOONG, T.S.Y. Adsorption of glyphosate onto activated carbon derived from waste newspaper. Desalination and Water Treatment, v. 24, n. 1-3, p. 321-326, 2010. https://doi.org/10.5004/ dwt.2010.1461

PARK, J.; REGALBUTO, J.R. A Simple, Accurate Determination of Oxide PZC and the Strong Buffering Effect of Oxide Surfaces at Incipient Wetness. Journal of Colloid and Interface Science, v. 175, n. 1, p. 239-252, out. 1995. https://doi.org/10.1006/jcis.1995.1452

PEREIRA, J. Remoção de pesticidas em água utilizando adsorventes a base de borra de café. Dissertação (Mestrado) - Universidade Federal de Goiás, Goiânia, 2010.

RAJASULOCHANA, P.; PREETHY, V. Comparison on efficiency of various techniques in treatment of waste and sewage water: a comprehensive review. Resource-Efficient Technologies, v. 2, n. 4, p. 175-184, 2016. https://doi. org/10.1016/j.reffit.2016.09.004

RUTHVEN, D.M. Principles of Adsorption and Adsorption Process. Nova York: John Wiley \& Sons, 1984.

SALES, P.F.; BERTOLI, A.C.; PINTO, F.M.; MAGRIOTIS, Z.M. Produção, Caracterização e Aplicação do Carvão Ativado Obtido a partir do Sabugo de Milho: A Busca pelo Reaproveitamento de um Resíduo Agroindustrial. Revista Virtual de Química, v. 7. n. 4, p. 1174-1188, 2015. http://dx.doi. org/10.5935/1984-6835.20150066

SALMAN, J.M.; ABID, F.M.; MUHAMMED, A.A. Batch study for pesticide glyphosate adsorption onto palm oil fronds activated carbon. Asian Journal of Chemistry, v. 24, n. 12, p. 5646-5648, 2012.

SEN, K.; DATTA, J.K.; MONDAL, N.K. Glyphosate adsorption by Eucalyptus camaldulensis bark-mediated char and optimization through response surface modeling Applied Water Science, v. 9, n. 7, p. 162, 2019. https://doi. org/10.1007/s13201-019-1036-3 
STREIT, A.F.M.; CÔRTES, L.N.; DRUZIAN, S.P.; GODINHO, M.; COLLAZZO, G.C.; PERONDI, D:; DOTTO, G.L. Development of high quality activated carbon from biological sludge and its application for dyes removal from aqueous solutions. Science of The Total Environment, v. 660, p. 277-287, 2019. https:// doi.org/10.1016/j.scitotenv.2019.01.027

STUART, B. Infrared Spectroscopy: Fundamentals and Applications. Sydney: John Wiley \& Sons, 2004.

TAN, I.A.W.; AHMAD, A.L.; HAMEED, B.H. Adsorption of basic dye using activated carbon prepared from oil palm shell: batch and fixed bed studies. Desalination, v. 225, n. 1-3, p. 13-28, 2008. https://doi.org/10.1016/j. desal.2007.07.005

THOMMES, M.; KANEKO, K.; NEIMARK, A.V:; OLIVER, J.P.; RODRIGUEZREINOSO, F.; ROUQUEROL, J.; SING, K.S.W. Physisorption of gases, with special reference to the evaluation of surface area and pore size distribution (IUPAC Technical Report). Pure and Applied Chemistry, v. 87, n. 9-10, p. 10511069, 2015. https://doi.org/10.1515/pac-2014-1117

TZASKOS, D.F.; MARCOVICZ, C.; DIAS, N.M.P.; ROSSO, N.D. Development of sampling for quantification of glyphosate in natural waters. Agricultural Sciences, v. 36, n. 4, p. 399-405, 2012. https://doi.org/10.1590/S141370542012000400003
WANG, H.; WANG, X:; CUI, Y.; XUE, Z:; BA, Y. Slow pyrolysis polygeneration of bamboo (Phyllostachys pubescens): Product yield prediction and biochar formation mechanism. Bioresource Technology, v. 263, p. 444-449, 2018. https://doi.org/10.1016/j.biortech.2018.05.040

WANG, J.; WANG, S. Preparation, modification and environmental application of biochar: A review. Journal of Cleaner Production, v. 227, p. 1002-1022, 2019. https://doi.org/10.1016/j.jclepro.2019.04.282

WESTERHOFF, P.; YOON, Y; SNYDER, S.; WERT, E. Fate of endocrinedisruptor, pharmaceutical, and personal care product chemicals during simulated drinking water treatment processes. Environmental Science and Technology, v. 39, n. 17, p. 6649-6663, 2005. https://doi.org/10.1021/ esO484799

YAMAGUCHI, N.U.; RUBIO, A.J.; BERGAMASCO, R. Carvão ativado impregnado com manganês e ferro para adsorção de glifosato: Cinética, isotermas e estudos termodinâmicos. Ambiente \& Agua, v. 14, p. 6, 2019. https://doi.org/10.4136/ambi-agua.2414

ZHOU, C.R.; LI, G.P.; JIANG, D.G. Estudo sobre o comportamento do glifosato adsorvente da fibra alcalescente FFA-1 a partir das águas residuais da produção de glifosato. Equilíbrio de Fase Fluida, v. 362, p. 69-73, 2014. https://doi.org/10.1016/j.fluid.2013.09.002 